\title{
Ganoderan (GDN) Regulates The Growth, Motility And Apoptosis Of Non-Small Cell Lung Cancer Cells Through ERK Signaling Pathway In Vitro And In Vivo
}

This article was published in the following Dove Press journal: OncoTargets and Therapy

\section{Weifeng Wang' \\ Xiaohui Gou' \\ Hua Xue' \\ Kai Liu ${ }^{2}$}

'Department of Thoracic Surgery, The First People's Hospital of Xianyang, Xianyang City, Shaanxi 7I2000, People's Republic of China; ${ }^{2}$ Department of Thoracic Surgery, The Central Hospital of Xianyang, Xianyang City, Shaanxi 712000, People's Republic of China
Correspondence: Kai Liu

The Central Hospital of Xianyang, No. 78, Renmin East Road, Weicheng District, Xianyang City, Shaanxi Province, People's Republic of China

Tel +86-29-33288793

Email hg5i533g@sina.com
Background: Lung cancer is the most common malignant tumor worldwide. About $90 \%$ of lung cancers are considered non-small cell lung cancer (NSCLC). Ganoderan (GDN) is one of the components of Ganoderma lucidum polysaccharides. Ganoderan A (GDNA), Ganoderan B (GDNB) and Ganoderan C (GDNC) were three polysaccharides isolated from the Ganoderma lucidum fruiting body.

Methods: Cell growth was measured by Cell Counting kit-8 and colony formation assay, while cell motility was measured by transwell assay and wound healing assay. Apoptosis was measured by flow cytometry analysis and TUNEL staining, and protein expression was detected by Western blotting and immunohistochemistry.

Results: Previous studies have shown that GDNB has the effects of hyperglycemic and kidney protection. However, the role of GDNB in tumors is currently unknown. This study elaborated the role of GDNB in NSCLC and its underlying molecular mechanisms. The results exerted that GDNB inhibited the growth of H510A and A549 cells by suppressing the expression of ki67 and PCNA. Besides, transwell assay and wound healing assay showed that GDNB inhibited invasion and migration of H510A and A549 cells in a concentrationdependent manner. Moreover, Western blotting also showed that GDNB downregulated the levels of N-cadherin, vimentin and Snail in H510A and A549 cells in a dose-dependent manner, while it upregulated the level of E-cadherin. Additionally, GDNB also promoted apoptosis of H510A and A549 cells by regulating the expression of Bcl-2, Bax, cleaved caspase 3 and cleaved PARP. Animal experiments revealed that GDNB inhibited tumor growth and metastasis, and induced apoptosis of tumor cells in vivo. Mechanically, GDNB suppressed the expression of Ras and c-Myc, and decreased the phosphorylation levels of MEK1/2 and ERK1/2.

Conclusion: Collectively, all data suggest that GDNB regulates the growth, motility and apoptosis of non-small cell lung cancer cells through ERK signaling pathway in vitro and in vivo. Keywords: non-small cell lung cancer, Ganoderan, extracellular signal-regulated protein kinase, mitogen-activated protein kinase, anticancer

\section{Introduction}

Lung cancer is the most common malignant tumor, and its morbidity and mortality account for $13 \%$ and $19.4 \%$, respectively. ${ }^{1}$ There are 1.8 million new cases and 1.6 million deaths of lung cancer each year. ${ }^{2}$ In China, it is estimated that one million new cases of lung cancer are expected to occur annually by 2025 . $^{3}$ About $90 \%$ of lung cancers are considered non-small cell lung cancer (NSCLC). ${ }^{4}$ Patients with advanced NSCLC cannot be treated surgically. ${ }^{5}$ Conventional chemotherapy is a 
good choice, but chemotherapeutic drugs such as cisplatin have great toxic and side effects on the body, and patients are prone to develop resistance to chemotherapeutic drugs. ${ }^{6}$ For these reasons, the five-year overall survival rate for patients with NSCLC is less than $15 \%{ }^{7}$ Therefore, exploring new therapeutic drugs with high efficacy and low side effects is of great significance for the treatment of NSCLC.

Ganoderma lucidum is one of the famous Chinese herbal medicines in China and has a history of more than 2,000 years. ${ }^{8}$ Ganoderma lucidum fruiting bodies have been considered effective for the treatment of various diseases for thousands of years. ${ }^{9}$ The polysaccharide extracted from Ganoderma lucidum has been developed into a clinical drug for the treatment of neurosis, polymyositis, dermatomyositis, atrophic myotonia and muscular dystrophy. ${ }^{8}$ In addition, Ganoderma lucidum polysaccharides exhibit antitumor activity against a variety of tumors, such as cervical cancer, ${ }^{10}$ lung cancer ${ }^{11}$ and prostate cancer, ${ }^{12}$ Hilcino et al isolated three polysaccharides from the Ganoderma lucidum fruiting body, namely, Ganoderan A (GDNA), Ganoderan B (GDNB) and Ganoderan C (GDNC). It was also found that GDA, GDNB and GDNC have hypoglycemic effects on normal mice. ${ }^{13,14}$ In addition, GDNB increases plasma insulin levels and decreases hepatic glycogen levels in normal and glucose-loaded mice. ${ }^{15}$ Besides, GDN has a protective effect on ADR-induced chronic glomerulonephritis in rats. ${ }^{16}$ However, the role of GDNB in lung cancer and its underlying molecular mechanisms remain unknown.

Extracellular signal-regulated protein kinase (ERK) signaling pathway is a classical mitogen-activated protein kinases (MAPKs) signal transduction pathway and plays an important role in cell proliferation, ${ }^{17}$ invasion, migration, ${ }^{18}$ differentiation and apoptosis. ${ }^{19}$ Previous studies have shown that the ERK signaling pathway is overactivated in most patients with advanced hepatocellular carcinoma. ${ }^{20}$ In lung cancer cells, Nereis Active Protease exhibits antiproliferative activity by inhibiting apoptosis of lung cancer cells via inhibiting phosphorylation of ERK. ${ }^{21}$ In addition, miR-330-3p promotes the growth, invasion and migration of NSCLC cells by activating the MAPK/ ERK signaling pathway. ${ }^{22}$ Mitogen-activated protein kinase (MEK) is a kinase that specifically activates ERK in the ERK pathway. Therefore, the ERK pathway was chosen to investigate whether GDNB has a certain inhibitory effect on NSCLC.
In the current study, we explored the role of GDNB in lung cancer and its underlying molecular mechanisms. Our results indicate that GDNB can significantly inhibit the growth and motility of lung cancer cells, and induce cell apoptosis by inactivating the ERK signaling pathway in vitro and in vivo. Our findings reveal that GDNB may be a potential anticancer drug in the treatment of lung cancer.

\section{Materials And Methods Cell Culture And Treatment}

Normal human lung fetal fibroblasts cell line WI-38 and non-small cell lung cancer cell lines (H510A and A549) were bought from the Cell Bank of Chinese Academy of Science (Shanghai, China) and cultured in RPMI1640 medium (Thermo Fisher Scientific, Massachusetts, USA) supplemented with $10 \%$ fetal bovine serum (FBS, Thermo Fisher Scientific, Massachusetts, USA) and 1\% penicillin/ streptomycin $(100 \mathrm{U} / \mathrm{mL}$, Sigma-Aldrich, St Louis, MO, USA) with $95 \% \mathrm{O}_{2} / 5 \% \mathrm{CO}_{2}$ at $37^{\circ} \mathrm{C}$. GDNB was bought from Hubei jusheng technology co. LTD (Wuhan, China), dissolved in RPMI1640 (Gibco, Invitrogen, Massachusetts, USA) and diluted to different concentrations $(0.25,0.5,1.5$, 3 and $5 \mathrm{mg} / \mathrm{mL}$ ). WI-38, H510A and A549 cells were subjected to various concentrations of $\operatorname{GDNB}(0.25,0.5$, $1.5,3$ and $5 \mathrm{mg} / \mathrm{mL}$ ) for $24 \mathrm{hrs}, 48 \mathrm{hrs}$ and $72 \mathrm{hrs}$, respectively.

\section{CCK8 Assay}

Cell viability was measured by Cell Counting kit-8 (CCK8; Dojindo Molecular Technologies, MD, Japan) assay according to the manufacturer's instructions. Briefly, WI$38, \mathrm{H} 510 \mathrm{~A}$ and A549 cells $(100 \mu \mathrm{l} /$ well $)$ were inoculated into 96-well plates for $24 \mathrm{hrs}$ and then subjected to various concentrations of GDNB $(0.25,0.5,1.5,3$ and $5 \mathrm{mg} / \mathrm{mL})$. Thereafter, the cells were maintained at $37^{\circ} \mathrm{C}$ with $5 \% \mathrm{CO}_{2}$ for $24 \mathrm{hrs}, 48 \mathrm{hrs}$ and $72 \mathrm{hrs}$, respectively. Furtherly, the cells were exposed to $10 \mu \mathrm{CCK}-8$ solution at $37^{\circ} \mathrm{C}$ for 1 hrs. The OD values were measured using a microplate reader (Thermo Fisher Scientific, Massachusetts, USA) at $450 \mathrm{~nm}$.

\section{Colony Formation Assay}

$\mathrm{H} 510 \mathrm{~A}$ and A549 cells were seeded in 24-well plates at a density of $500 \mu \mathrm{l} / \mathrm{well}$ and incubated at $37^{\circ} \mathrm{C}$ for $48 \mathrm{hrs}$. Subsequently, H510A and A549 cells were subjected to different concentrations $(0.25,0.5$ and $1 \mathrm{mg} / \mathrm{mL})$ of GDNB for $48 \mathrm{hrs}$, and the complex medium was replaced 
every 2 to 3 days. The cells were cultured for two weeks to form colonies. After that, the cells were stained with crystal violet $(0.4 \mathrm{~g} / \mathrm{L})$ and scored by a microscope. Colonies were counted only when a single colony contained $>100$ cells. Each assay was performed in triplicate.

\section{Transwell Assay}

Invasive ability of H510A and A549 cells was measured by transwell assay. H510A and A549 cells were seeded in 24-well plates at a density of $500 \mu \mathrm{l} /$ well and incubated at $37^{\circ} \mathrm{C}$ for $48 \mathrm{hrs}$. Subsequently, H510A and A549 cells were subjected to different concentrations $(0.25,0.5$ and $1 \mathrm{mg} / \mathrm{mL})$ of GDNB for $48 \mathrm{hrs}$. Thereafter, the cells $(4.5 \times$ $10^{4}$ ) were harvested, re-suspended in $200 \mu \mathrm{l}$ of serum-free medium and transferred to an upper chamber covered with a MatrigelTM Matrix (BD BiocoatTM, Beijing, China) for incubation. Then, $750 \mu \mathrm{l}$ of complete medium was added to the basal side chamber. After incubation at $37^{\circ} \mathrm{C}$ for 24 hrs, the cells were fixed with ice-cold methanol for $5 \mathrm{~min}$ at room temperature and stained with $0.1 \%$ crystal violet (Merck, Darmstadt, Germany) for $5 \mathrm{~min}$ at room temperature. The remaining cells on the upper chambers were gently removed with a wet cotton swab, and the cells in the low chambers were stained with Hematoxylin dye $(500 \mu \mathrm{l})$ for $10 \mathrm{~min}$ and photographed using a microscope (Leica Microsystems, Wetzlar, Germany) with five randomly selected image fields.

\section{Wound Healing Assay}

Migration ability was detected using the Wound healing assay. Mitomycin C (10 $\mu \mathrm{g} / \mathrm{mL})$ was applied to prevent the self-proliferation of cells. ${ }^{23}$ Briefly, H510A and A549 cells were exposed to various concentrations of GDNB $(0.25$, 0.5 and $1 \mathrm{mg} / \mathrm{mL}$ ) for $48 \mathrm{hrs}$. Then, the cells were seeded in 6-well plates at a density of $2 \times 10^{6}$ cells/well and incubated at $37^{\circ} \mathrm{C}$ until monolayer cells were formed. Subsequently, monolayer cells were cut with a sterile $200 \mu \mathrm{l}$ pipette tip to create an artificial wound. Thereafter, cells were cultured under serum-starved conditions for 24 hrs. After that, the cells were washed with PBS for three times to remove the fallen cells. The cell migration was observed with a phase contrast microscope, and images were taken with a 600D camera (Canon, Japan).

\section{Western Blotting}

H510A and A549 cells were subjected to various concentrations of $\operatorname{GDNB}(0.25,0.5$ and $1 \mathrm{mg} / \mathrm{mL})$ for $48 \mathrm{hrs}$. Then, the cells were collected and resuspended in RIPA lysis buffer
(Beyotime, Beijing, China) with a protease inhibitor phenylmethanesulfonyl fluoride (PMSF) according to the manufacturer's instructions. Thereafter, the cell lysates were collected, and the protein content was detected by using a BCA assay (Takara, Dalian, China) according to the manufacturer's instructions and UV spectrophotometer. Then, proteins $(20 \mu \mathrm{g})$ were separated by $10 \%$ SDS-PAGE, and then the protein electrophoresis gel was transferred to PVDF membrane (Millipore, Billerica, MA, USA). Next, the membranes were hybridized with primary antibodies according to the manufacturer's instruction manual. After that, the membranes were incubated with a secondary antibody Goat AntiRabbit IgG H\&L (HRP) preadsorbed (ab7090, Abcam, UK) for $2 \mathrm{hrs}$ at room temperature. After washing with TBST for three times, the blot was visualized with chemiluminescence detection kit (Advanstar, Cleveland, OH, USA) and quantified by ImageJ software. The intensity of each band is normalized to GAPDH. The primary antibodies were listed as follows: Ki67 (ab16667, 1:5000, Abcam, UK), PCNA (ab92552, 1:5000, Abcam, UK), $\beta$-actin (ab179467, 1:5000, Abcam, UK), N-cadherin (ab18203, 1:5000, Abcam, UK), E-cadherin (ab1416, 1:5000, Abcam, UK), Vimentin (ab8978, 1:5000, Abcam, UK), Snail (ab182858, 1:5000, Abcam, UK), Bcl-2 (ab182858, 1:5000, Abcam, UK), Bax (ab182733, 1:5000, Abcam, UK), Cleaved caspase 3 (ab32042, 1:5000, Abcam, UK), Cleaved PAPR (\#5625, 1:1000, Cell Signaling Technology, USA), Ras (ab52939, 1:5000, Abcam, UK), MEK1/2 (\#8727, 1:1000, CST, USA), p-MEK1/2 (\#2338, 1:1000, CST, USA), ERK1/2 (ab17942, 1:5000, Abcam, UK), p-ERK1/2 (ab214362, 1:5000, Abcam, UK) and c-Myc (ab32072, 1:5000, Abcam, UK).

\section{Flow Cytometry Analysis}

Apoptosis was detected by double staining with Annexin V-fluorescein isothiocyanate (V-FITC) and propidium iodide (PI). H510A and A549 cells were seeded in 6well plates $\left(1.0 \times 10^{5}\right.$ cells $\left./ \mathrm{mL}\right)$ and incubated at $37^{\circ} \mathrm{C}$ for 24 hrs. Subsequently, H510A and A549 cells were subjected to various concentrations of GDNB $(0.25,0.5$ and $1 \mathrm{mg} / \mathrm{mL}$ ) for $48 \mathrm{hrs}$. Thereafter, cells were harvested and resuspended, and then the cells were stained with PI (10 $\mu \mathrm{g} / \mathrm{mL}$, Sigma-Aldrich; Merck KGaA, Darmstadt, Germany) and Annexin V-FITC (50 $\mu \mathrm{g} / \mathrm{mL}$, BD Biosciences, Franklin Lakes, NJ, USA) for $15 \mathrm{~min}$ at room temperature in the dark. Cell apoptosis was analyzed using a FACScalibur flow cytometer (FACScan; BD Biosciences). 


\section{Establishment Of Mouse Model Of Lung Cancer Bearing Tumor}

In vivo experiments were authorized by the Institutional Animal Care and Use Committee of the First People's Hospital of Xianyang and carried out according to the Guide of the National Institutes of Health for the care and use of experimental animals. Sixty Balb/c-nude mice (8-10 weeks old, 20-25 g weight) were obtained from the Animal Center of the First People's Hospital of Xianyang (Shaanxi, China) and with access to free food and water. A549 cells were cultured in RPMI1640 medium (Thermo Fisher Scientific, Massachusetts, USA) supplemented with 10\% FBS (Thermo Fisher Scientific, Massachusetts, USA) and $1 \%$ penicillin/streptomycin $(100 \mathrm{U} / \mathrm{mL}$, SigmaAldrich, St Louis, MO, USA) with $95 \% \mathrm{O}_{2} / 5 \% \mathrm{CO}_{2}$ at $37^{\circ} \mathrm{C}$. Thereafter, A549 cells $\left(1.0 \times 10^{7}\right)$ were suspended in $0.9 \%$ saline $(200 \mu \mathrm{l})$ and then subcutaneously injected into the right flank of mice to construct lung cancer-bearing tumor model. After successful modeling, lung tumorbearing mice were randomly divided into 4 groups (ten in each group): Control group (The mice were intragastrically administered with $0.9 \%$ saline) and Administration groups (The mice were intragastrically administered with GDNB at $10,20,30 \mathrm{mg} / \mathrm{kg}$, respectively). After eight weeks later, the mice were sacrificed, and tumors were taken out, weight and photograph. Then, the tumor tissues were cut into pieces and stored for subsequent research.

\section{Terminal Transferase-Mediated dUTP Nick End Labeling (TUNEL) Assay}

Tumor cell apoptosis was detected by in situ cell death assay kit according to the manufacturer's instructions (Roche, Mannheim, Germany) using TUNEL assay. In brief, the tumor tissue embedded in paraffin was cut into $5 \mu \mathrm{m}$-thickness pieces. After that, paraffin section was dewaxed with xylene for $20 \mathrm{~min}$ and hydrated with gradient ethanol (100\%, 95\%, 90\%, 80\% and $70 \%)$. Then, the sections were washed with PBS for three times and permeable with proteinase $\mathrm{K}$ at $37^{\circ} \mathrm{C}$ for $20 \mathrm{~min}$. Thereafter, the sections were fixed with $4 \%$ paraformaldehyde for $15 \mathrm{~min}$ at room temperature and blocked with $3 \% \mathrm{H}_{2} \mathrm{O}_{2}$ for 10 min. After washing with PBS for three times (5 min per time), the sections were incubated with TUNEL reagent at $37^{\circ} \mathrm{C}$ for $1 \mathrm{hr}$. Whereafter, the labeled DNA was observed using a peroxidase-conjugated anti-fluorescein antibody. The percentage of tunel positive cells to the total number of cells is considered to be the apoptotic rate.

\section{Immunohistochemistry}

IHC assay was employed to detect the expression of caspase 3, Ki67 and vimentin. The tumor tissue embedded in paraffin was cut into $5 \mu \mathrm{m}$-thickness pieces, dewaxed with xylene for $20 \mathrm{~min}$, and rehydrated with gradient ethanol $(100 \%, 95 \%, 90 \%, 80 \%$ and $70 \%)$. Then, $\mathrm{H}_{2} \mathrm{O}_{2}$ solution was added to block endogenous peroxidase activity. Thereafter, $10 \%$ goat serum was added for $1 \mathrm{hrs}$ to prevent non-specific reactions. Subsequently, tumor tissues were incubated with primary antibodies anti-caspase 3 (\#9662, 1:1000, CST, USA), anti-Ki67 (\#12202, 1:400, CST, USA) and anti-vimentin (\#5741, 1:200, CST, USA) overnight at $4^{\circ} \mathrm{C}$ and then incubated with HRP-linked Antibody (\#7074, CST, USA) at $37^{\circ} \mathrm{C}$ for $1 \mathrm{hr}$. Finally, the samples were co-cultured with 3,3'-diaminobenzidine and observed under a light microscope (Nikon).

\section{Statistical Analysis}

Data are expressed as mean \pm standard deviation (SD) of at least three independent experiments. Students' $t$-test, one-way ANOVA and Bonferroni test were used to evaluate the differences between the groups. The difference was statistically significant at $\mathrm{P}<0.05$.

\section{Results}

\section{GDNB Inhibits The Growth Of Non- Small Cell Lung Cancer Cells}

The cytotoxicity of GDNB against WI-38, H510A and A549 was determined by CCK 8 assay. WI-38, H510A and A549 cells were subjected to different concentrations of GDNB $(0.25,0.5,1.5,3$ and $5 \mathrm{mg} / \mathrm{mL})$ for $24 \mathrm{hrs}, 48 \mathrm{hrs}$ and $72 \mathrm{hrs}$, respectively. Cell viability was shown in Figure 1A, B and C. GDNB treatment for $24 \mathrm{hrs}$ and 48 hrs had no significant effect on the viability of WI-38 cells, but significantly decreased the viability of A549 and H510A cells in a concentration-dependent manner. After treatment with GDNB for $72 \mathrm{hrs}$, the low concentration of GDNB had no obvious side effects on the viability of WI-38 cells. However, when the dose of GDNB exceeded $1.5 \mathrm{mg} /$ $\mathrm{mL}$, the viability of WI-38 cells was significantly reduced. Besides, GDNB treatment for $72 \mathrm{hrs}$ showed a more potent inhibitory effect on the viability of A549 and H510A cells. Therefore, the subsequent experiments in this study used a treatment time of $48 \mathrm{hrs}$. Next, we explored the effects of different concentrations of GDNB $(0.25,0.5$ and $1 \mathrm{mg} / \mathrm{mL})$ on the colony formation of A549 and H510A cells. As shown in Figure 1D and E, GDNB treatment reduced the 

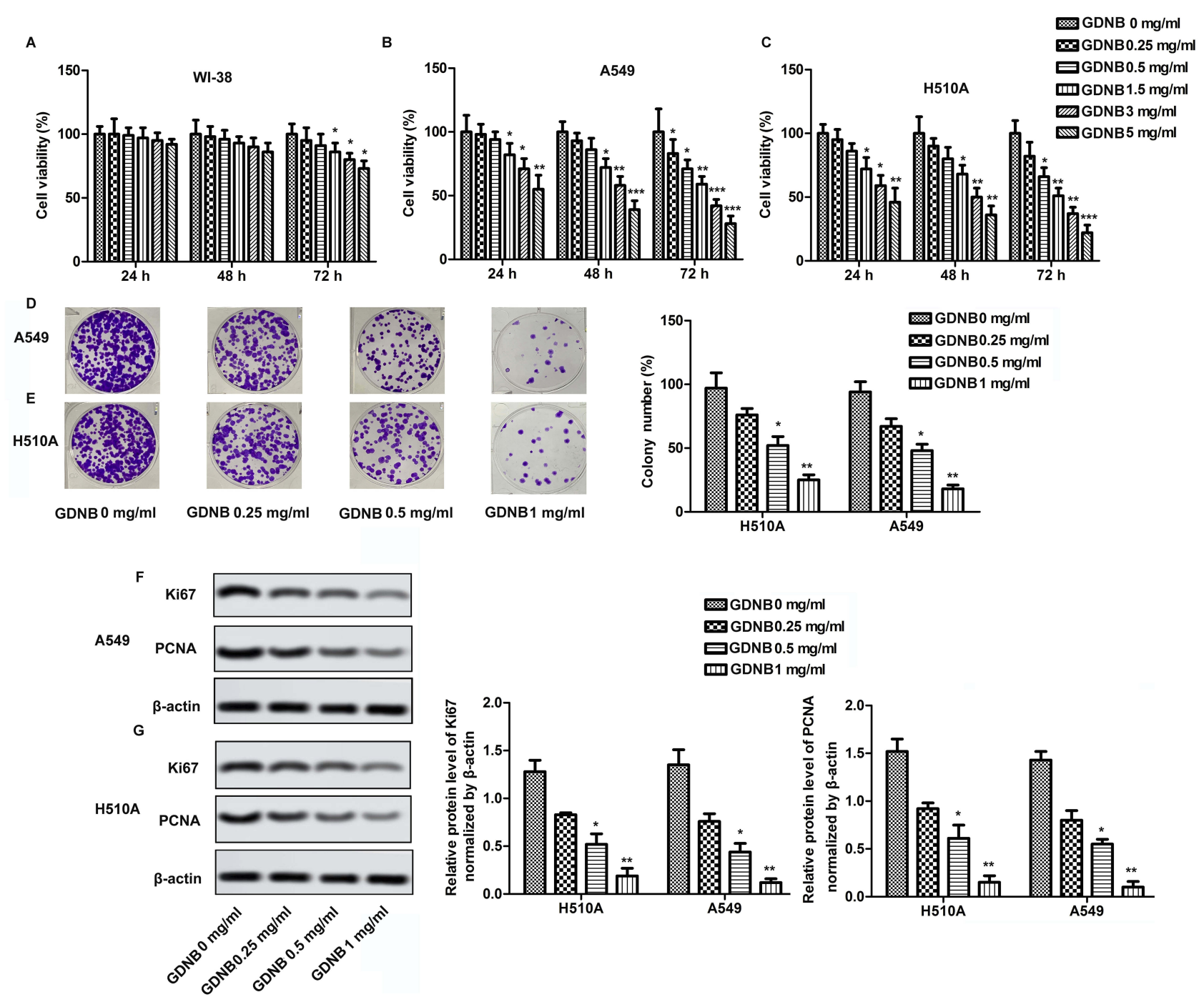

Figure I GDNB inhibits the growth of non-small cell lung cancer cells. WI-38, H5 IOA and A549 cells were subjected to different concentrations of GDNB (0.25, 0.5, I.5, 3 and $5 \mathrm{mg} / \mathrm{mL}$ ) for $24 \mathrm{hrs}, 48 \mathrm{hrs}$ and $72 \mathrm{hrs}$, respectively. (A) Cell viability of WI-38 cells was measured by CCK8 assay. (B) Cell viability of H5IOA cells was measured by CCK8 assay. (C) Cell viability of A549 cells was measured by CCK8 assay. (D-G) A549and H5I0A cells were subjected to different concentrations of GDNB ( 0.25 , 0.5 and $\mathrm{I} \mathrm{mg} / \mathrm{mL}$ ) for 48 hrs. (D-E) Cell growth of A549 and H5IOA cells was measured by colony formation assay. (F-G) The protein levels of Ki67 and PCNA in H5 I0A and A549 cells were measured by Western blotting. $\beta$-actin was used as internal reference. $(* p<0.05, * * p<0.01$, $* * * p<0.00$ I vs control group).

colonies of A549 and H510A cells in a concentrationdependent manner. Similarly, Western blotting analysis also showed that GDNB treatment decreased the expression of proliferating marker proteins ki67 and PCNA in H510A and A549 cells in a concentration-dependent manner (Figure $1 \mathrm{~F}$ and $\mathrm{G}$ ). All these data indicate that GDNB inhibits the growth of non-small cell lung cancer cells.

\section{GDNB Inhibits Invasion, Migration And Epithelial-Mesenchymal Transition (EMT) In Non-Small Cell Lung Cancer Cells}

Invasion and migration were measured by Transwell and Wound healing assays, respectively. As shown in Figure 2A and B, different concentrations of GDNB treatment $(0.25$, 0.5 and $1 \mathrm{mg} / \mathrm{mL}$ ) significantly inhibited the ability of H510A and A549 cells to invade compared with the control group. Besides, the ability of H510A and A549 cells to migrate was also inhibited by GDNB in a concentrationdependent manner (Figure 2C and D). EMT is a process in which polar epithelial cells transform into mesenchymal cells with migration ability. The EMT process is accompanied by cell morphological changes and is closely related to the invasion and metastasis of tumor cells. Therefore, this study further explored the effect of GDNB on EMT process. As shown in Figure 2E and F, the structure of the cells in the control group was loose and irregular, accompanied by 
A

B

A549
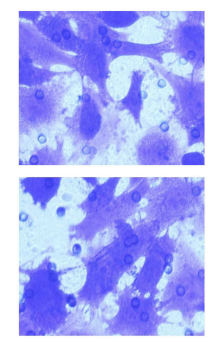

GDNB $\quad 0 \mathrm{mg} / \mathrm{ml}$

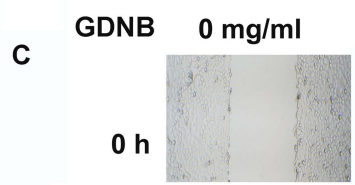

H510A

$24 \mathrm{~h}$

D

A549

$24 \mathrm{~h}$

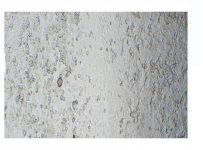

h
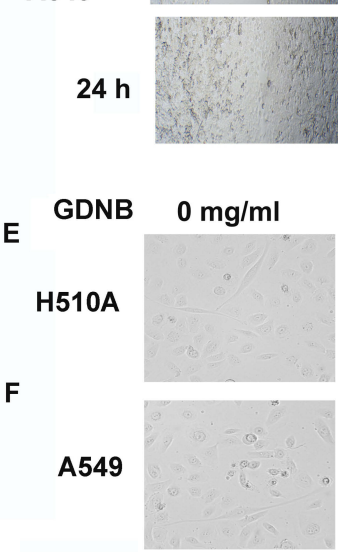

G
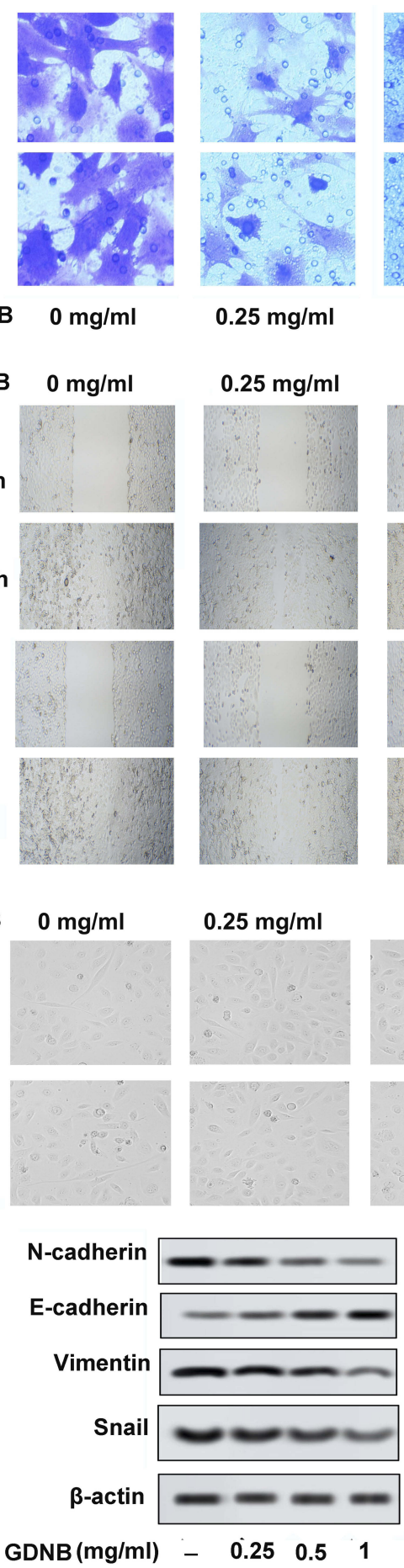

$0.25 \mathrm{mg} / \mathrm{ml}$
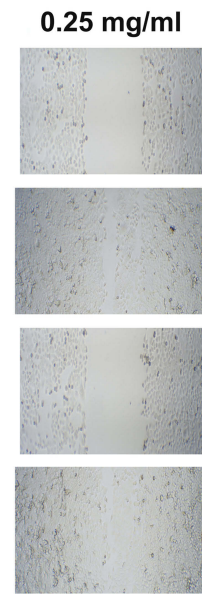

$0.25 \mathrm{mg} / \mathrm{ml}$
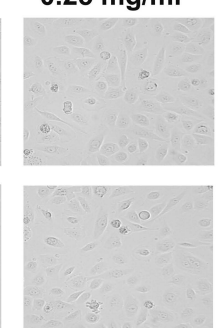
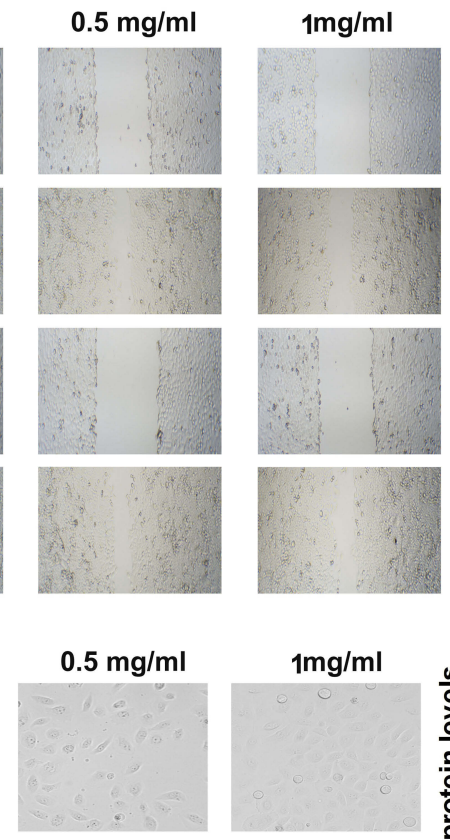

$1 \mathrm{mg} / \mathrm{ml}$

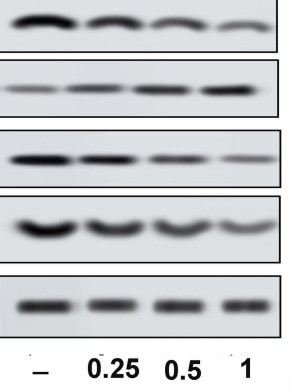

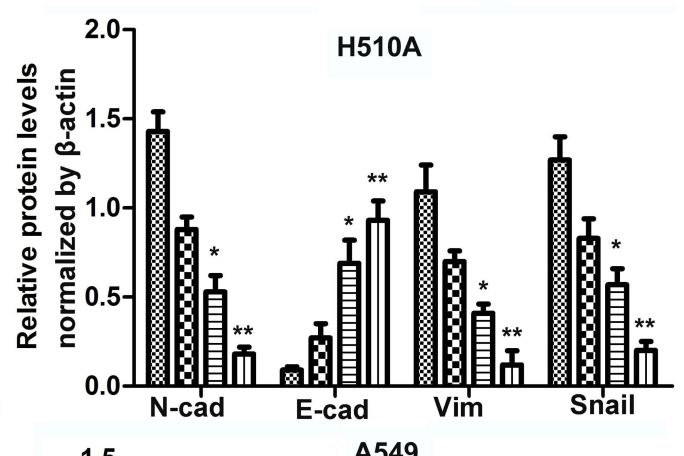
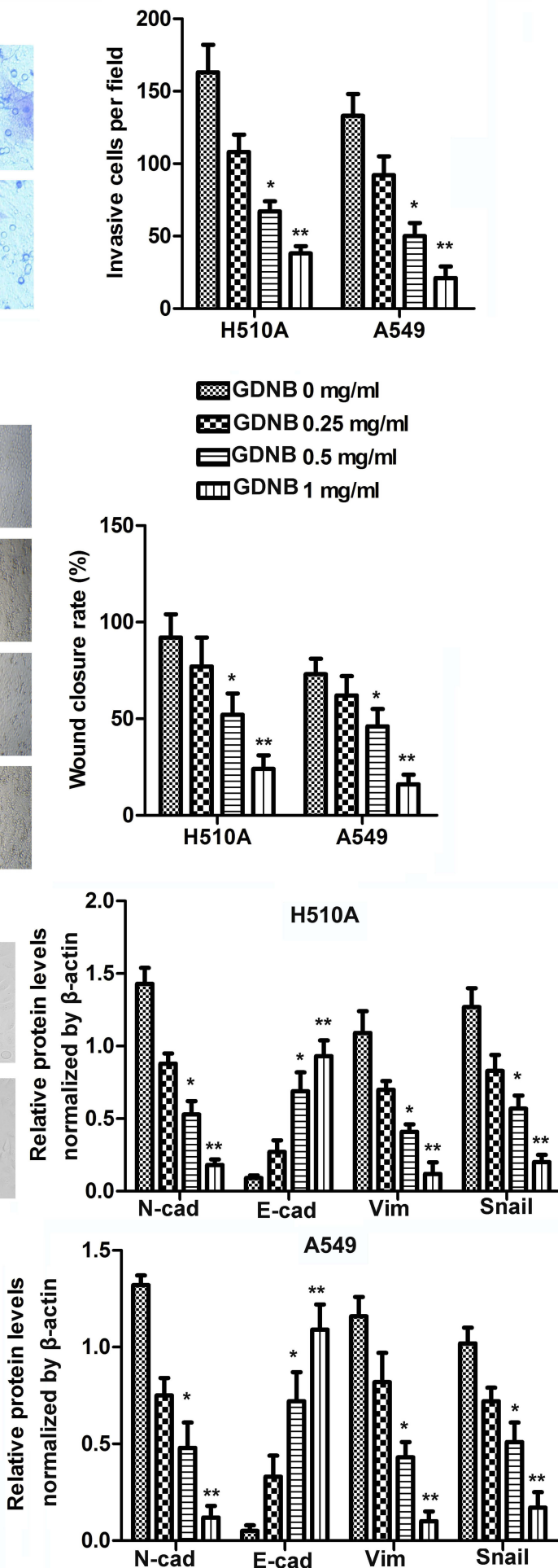

Figure 2 GDNB inhibits invasion, migration and EMT in non-small cell lung cancer cells. H5IOA and A549 cells were subjected to different concentrations of GDNB (0.25, 0.5 and $\mathrm{I} \mathrm{mg/mL}$ ) for $48 \mathrm{hrs}$. (A and B) Invasion of H5IOA and A549 cells was measured by Transwell assay. (C and D) Migration of H5IOA and A549 cells was measured by Wound healing assay. (E and $\mathbf{F}$ ) Cell morphology was examined by microscopy during EMT process. (G) The protein levels of $\mathrm{N}$-cadherin, E-cadherin, vimentin and Snail in $\mathrm{H} 5 \mathrm{IOA}$ and A549 cells were measured by Western blotting. $\boldsymbol{\beta}$-actin was used as internal reference. $\left({ }^{*} p<0.05\right.$, $*^{*} p<0.0 \mathrm{I}$ vs control group).

weak adhesion. Besides, the morphology of cells changed from cube to fusiform. However, after GDNB treatment, there was an obvious boundary between cells. The connections and adhesion between cells also become closer. The morphology of the cells also changed obviously. Additionally, increase of E-cadherin and decrease of 
Vimentin, N-cadherin and Snail expression are the fundamental events in EMT. Thus, the study further detected the expression of E-cadherin, Vimentin, N-cadherin and Snail. As shown in Figure 2G, Western blotting showed that GDNB treatment also decreased the levels of mesenchymal marker proteins (N-cadherin, vimentin and Snail) in H510A and A549 cells in a dose-dependent manner, and increased the level of epithelial marker protein (E-cadherin). Taken together, these results indicate that GDNB inhibits invasion, migration and EMT in non-small cell lung cancer cells.

\section{GDNB Promotes Apoptosis In Non-Small Cell Lung Cancer Cells}

Next, this study further investigated the effect of GDNB on apoptosis. H510A and A549 cells were subjected to GDNB treatment $(0.25,0.5$ and $1 \mathrm{mg} / \mathrm{mL})$ for $48 \mathrm{hrs}$. Then, apoptosis was detected by double staining with Annexin V-FITC and PI using flow cytometry analysis. As shown in Figure 3A, GDNB treatment $(0.25,0.5$ and 1 $\mathrm{mg} / \mathrm{mL}$ ) significantly induced apoptosis in H510A cells from $3.8 \%$ to $4.1 \%, 5.3 \%$ and $9.7 \%$. Likewise, GDNB treatment $(0.25,0.5$ and $1 \mathrm{mg} / \mathrm{mL})$ significantly induced apoptosis in A549 cells from $6.4 \%$ to $7.2 \%, 8.1 \%$ and 9.2\% (Figure 3B). Furtherly, Western blotting showed that GDNB treatment promoted the expression of apoptosis-associated proteins Bax, cleaved caspase 3 and cleaved PARP in H510A and A549 cells, while inhibiting the expression of anti-apoptotic protein Bcl-2 (Figure 3C and D). All these results show that GDNB promotes apoptosis in non-small cell lung cancer cells.

\section{GDNB Inhibits The Development Of Non-Small Cell Lung Cancer By Inactivating The ERK Pathway}

Western blotting was used to explore the underlying molecular mechanisms of GDNB in non-small cell lung cancer. As shown in Figure 4A, GDNB $(0.25,0.5$ and $1 \mathrm{mg} / \mathrm{mL})$ inhibited the expression of Ras and c-Myc in A549 cells in a concentration-dependent manner. Besides, GDNB also dose-dependently inhibited the phosphorylation of MEK1/ 2 and ERK1/2, demonstrating that GDNB might inactivate the ERK pathway. As expected, after addition of the ERK pathway activator Ceramide C6 (CC6, $10 \mu \mathrm{M})$, the levels of Ras, c-Myc, p-MEK1/2 and p-ERK1/2 were significantly increased, indicating that CC6 significantly reversed the inhibitory effect of GDNB on ERK pathway (Figure 4B). Furtherly, functional experiments showed that CC6 reversed the effects of GDNB on the growth, apoptosis, invasion and migration of A549 cells as well (Figure 4C-F). In general, these results indicate that GDNB inhibits the development of non-small cell lung cancer by inactivating the ERK pathway.

\section{GDNB Inhibits Tumor Formation In Vivo Through The ERK Pathway}

In vivo studies showed that GDNB administration $(10,20$, $30 \mathrm{mg} / \mathrm{kg}$ ) dose-dependently reduced tumor size and weight in tumor-bearing mice compared to the control group (Figure 5A and B). Mechanically, Western blotting further indicated that GDNB significantly inhibited the expression of Ras, c-Myc, p-MEK1/2 and p-ERK1/2 in tumor tissues (Figure 5C). Besides, TUNEL staining showed the effect of GDNB on tumor cell apoptosis. As shown in Figure 5D, the number of brown-stained positive cells was increased in a dose-dependent manner after treatment with different concentrations of GDNB compared with the control group, indicating that GDNB treatment $(10,20,30 \mathrm{mg} / \mathrm{kg})$ significantly promoted apoptosis of tumor cells. In addition, IHC analysis showed that the positive cells of caspase $3, \mathrm{Ki} 67$ and Vimentin was significantly decreased, indicating that GDNB treatment $(10,20,30 \mathrm{mg} / \mathrm{kg})$ inhibited the expression of caspase $3, \mathrm{Ki} 67$ and Vimentin in tumor tissues (Figure 5E). In short, these data indicate that GDNB might inhibit tumor formation and induced apoptosis by regulating the expression of $\mathrm{Ki} 67$ and caspase 2 in vivo through inactivating the ERK pathway.

\section{Discussion}

Malignant tumors, as one of the major public health problems that threaten human survival, greatly endanger human health. $^{24}$ Therefore, it is of great significance to seek new therapeutic drugs for malignant tumors. NSCLC is the most common cancer in the world and is the leading cause of cancer death in men and women. ${ }^{25}$ Although the treatment of NSCLC has made some progress in recent years, the prognosis is still very poor. Tumor metastasis remains the leading cause of high recurrence and mortality in NSCLC, with approximately $90 \%$ of NSCLC patients eventually dying from tumor metastasis. ${ }^{26}$ This study found that GDNB inhibited the invasion and migration of NSCLC cells in a dose-dependent manner and prevented the EMT process, indicating that GDNB has a significant inhibitory effect on NSCLC metastasis. Besides, GDNB can inhibit the growth of NSCLC cells and accelerate apoptosis, indicating 

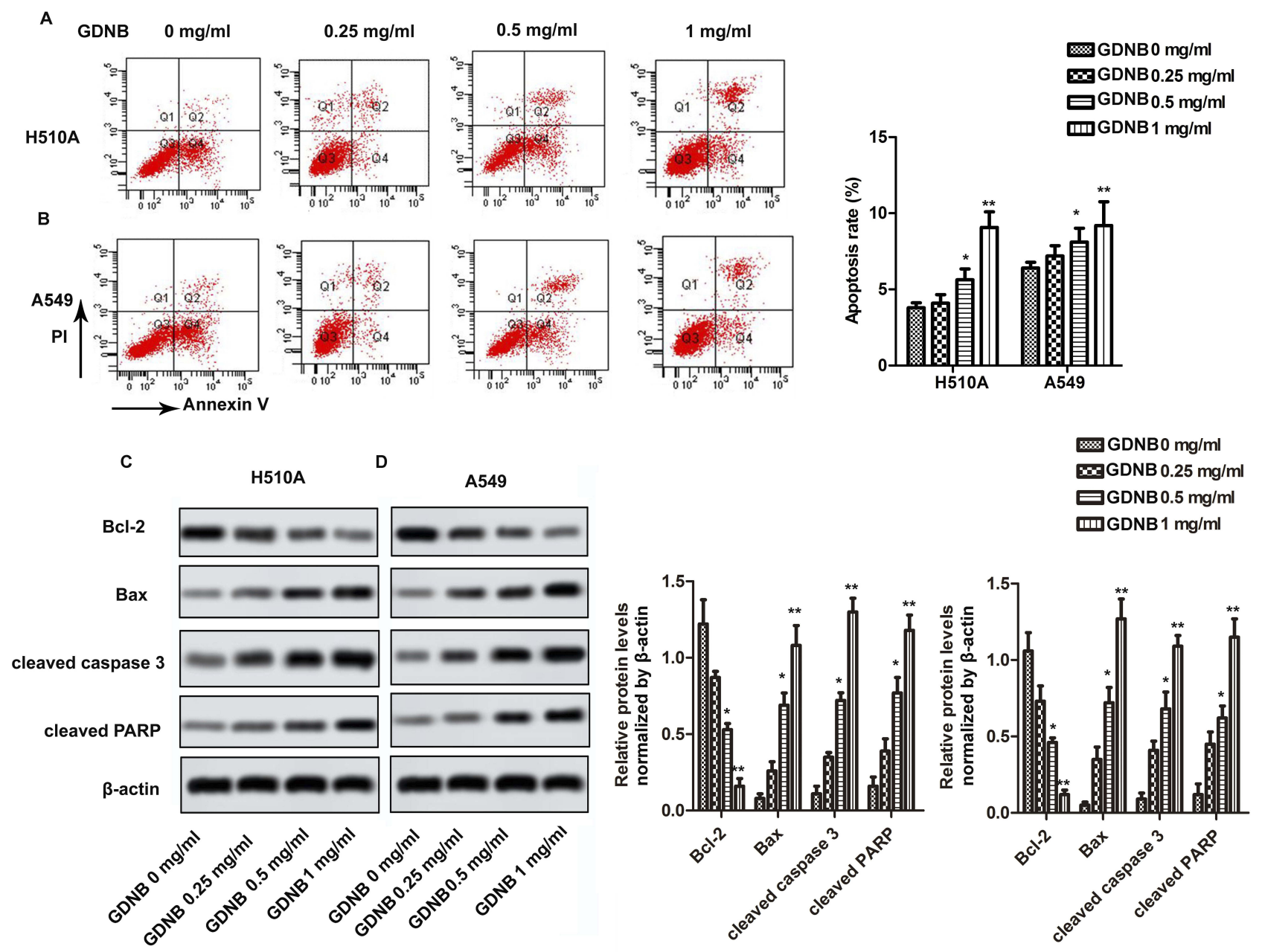

Figure 3 GDNB promotes apoptosis in non-small cell lung cancer cells. H5IOA and A549 cells were subjected to different concentrations of GDNB (0.25, 0.5 and I mg/mL) for 48 hrs. (A and B) Apoptotic rates of H5IOA and A549 cells were measured by flow cytometry analysis. (C and D) The protein levels of Bcl-2, Bax, cleaved caspase 3 and cleaved PARP in H5IOA and A549 cells were measured by Western blotting. $\beta$-actin was used as internal reference. ( ${ }^{*} p<0.05$, $*^{*} p<0.01$ vs control group).

that GDNB has an inhibitory effect on the occurrence of NSCLC.

As the main active ingredient of the Ganoderma lucidum, Ganoderma lucidum polysaccharide has significant activities such as immunoregulation, ${ }^{27}$ anti-cancer, ${ }^{28}$ antiinflammatory, ${ }^{29}$ anti-aging, ${ }^{30}$ hyperglycemic ${ }^{31}$ and liver protection. $^{32}$ In 2010, the State Food and Drug Administration (SFDA) approved Ganoderma. sinense polysaccharide (GSP) as adjunctive therapy during cancer treatment for leukopenia and hematopoietic damage caused by chemotherapy/radiation therapy. ${ }^{8}$ Guo et al pointed out that a single system of Ganoderma lucidum polysaccharide and soybean oil microemulsion can significantly inhibit the tumor growth of A549 tumor-bearing nude mice, and can significantly improve the serum immune index of nude mice. ${ }^{11}$ In addition, Wang et al found that GL-PS can improve serum interleukin-2, tumor necrosis factor- $\alpha$ and interferon- $\gamma$. The concentration enhances the cytotoxic activity of natural killer cells and $\mathrm{T}$ cells, promotes the functional maturation of dendritic cells, thereby inhibiting the growth of glioma and prolonging the survival time of rats. ${ }^{33}$ Zhao et al showed that GLP has an inhibitory effect on cell growth, cell cycle and cell migration. The inhibition of cell migration by GLP may be achieved by the PRMT6 signal transduction pathway. ${ }^{34}$ Ganoderan is a hypoglycemic polysaccharide derived from the aqueous extract of Ganoderma lucidum. ${ }^{13}$ In addition, Zhong et al found that Ganoderan can alleviate renal tissue pathological damage and improve renal function. ${ }^{16}$ However, there are still few studies on the effect of ganoderan on tumor. This study explored the role of Ganoderan B in NSCLC and its underlying molecular mechanisms. It was found that low doses of Ganoderan B had no significant side effects on normal 


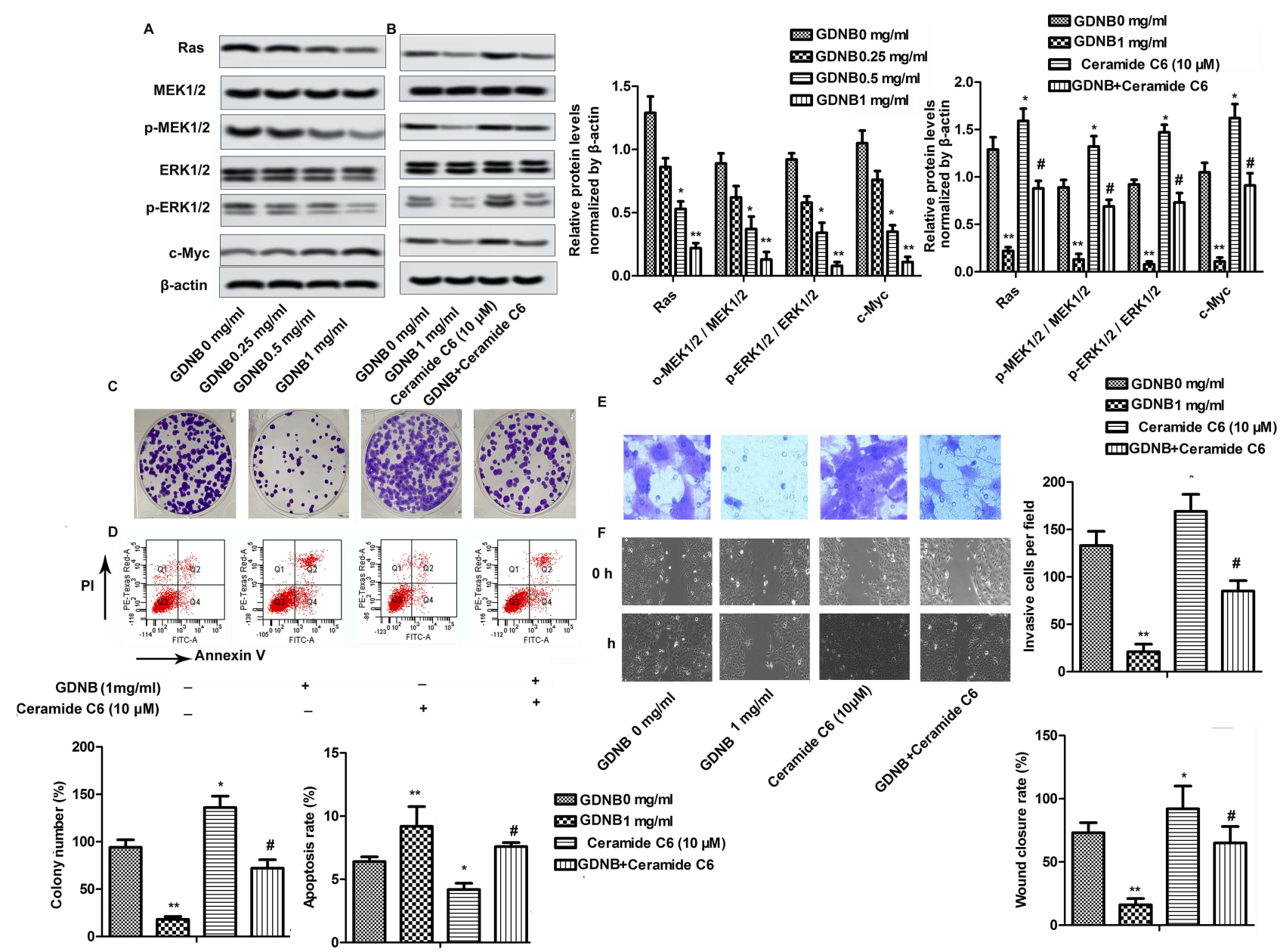

Figure 4 GDNB inhibits the development of non-small cell lung cancer by inactivating the ERK pathway. (A) A549 cells were subjected to different concentrations of GDNB $(0.25,0.5$ and $I \mathrm{mg} / \mathrm{mL})$ for 48 hrs. The protein levels of Ras, c-Myc, MEKI/2, p-MEKI/2, ERKI/2 and p-ERKI/2 were measured by Western blotting. $\boldsymbol{\beta}$-actin was used as internal reference. ( ${ }^{*} p<0.05$, ${ }^{*} p<0.01$ vs control group) $(\mathbf{B}-\mathbf{F})$ A549 cells were subjected to I $\mathrm{mg} / \mathrm{mL}$ GDNB or/and Ceramide C6 (I0 $\mu$ M) for 48 hrs. (B) The protein levels of Ras, c-Myc, MEKI/2, p-MEKI/2, ERKI/2 and $p$-ERKI/2 were measured by Western blotting. $\beta$-actin was used as internal reference. $(* p<0.05$, $* * p<0.01$ vs control group; ${ }^{*} p<0.05$ vs Ceramide C6 group) (C) Cell growth of H5I0A and A549 cells was measured by colony formation assay. (D) Apoptotic rate of A549 cells was measured by flow cytometry analysis. (E) Invasion of A549 cells was measured by Transwell assay. (F) Migration of A549 cells was measured by Wound healing assay. $\left({ }^{*} p<0.05\right.$, ${ }^{* *} p<$ 0.01 vs control group; ${ }^{\#} p<0.05$ vs Ceramide C6 group).

lung cancer cells. Moreover, GDNB can inhibit the growth, invasion and migration of NSCLC cells in vitro and in vivo, and induce cell apoptosis. Further mechanistic studies have shown that GDNB may achieve anti-tumor effects on NSCLC by regulating ERK signaling pathway.

An increasing amount of evidence suggests that abnormal regulation of ERK plays a key role in cell proliferation and survival. ${ }^{35,36}$ Tang et al pointed out that ERK/CREB signaling pathway can be inhibited by cancer-testis antigen family 45 member A1 after siRNA interference, and the inactivated ERK/CREB pathway prevents proliferation, metastasis and invasion of lung cancer cells. ${ }^{37}$ Yue et al found that the ERK/p38, AKT/mTOR and ERK signaling pathways may be negatively affected by ferulic acid (FA) derivative FXS-3, thereby inhibiting the proliferation and metastasis of human lung cancer A549 cells, inducing apoptosis and cell cycle arrest of A549 cells in G0/G1 phase. ${ }^{38}$ Chang et al pointed out that Fatty acid synthase can down-regulate AKT/ERK pathway, which involved in glucose metabolism and ultimately alters the malignant phenotype in lung cancer cells. ${ }^{39}$ Interestingly, previous studies have shown that traditional Chinese medicine can inhibit the development of lung cancer by regulating the activation of the ERK pathway. For example, Jiang et al revealed that Hydroxysafflor yellow A inhibits LPS-mediated proliferation, migration, invasion and EMT of A549 and H1299 cells by inactivating PI3K/Akt/mTOR and ERK/MAPK signaling pathways. ${ }^{40}$ Similarly, this study found that, as a polysaccharide, GDNB dose-dependently inhibits the expression and phosphorylation of ERK pathway-associated proteins (Ras, MEK1/2, ERK1/2 and c-Myc). Surprisingly, the 


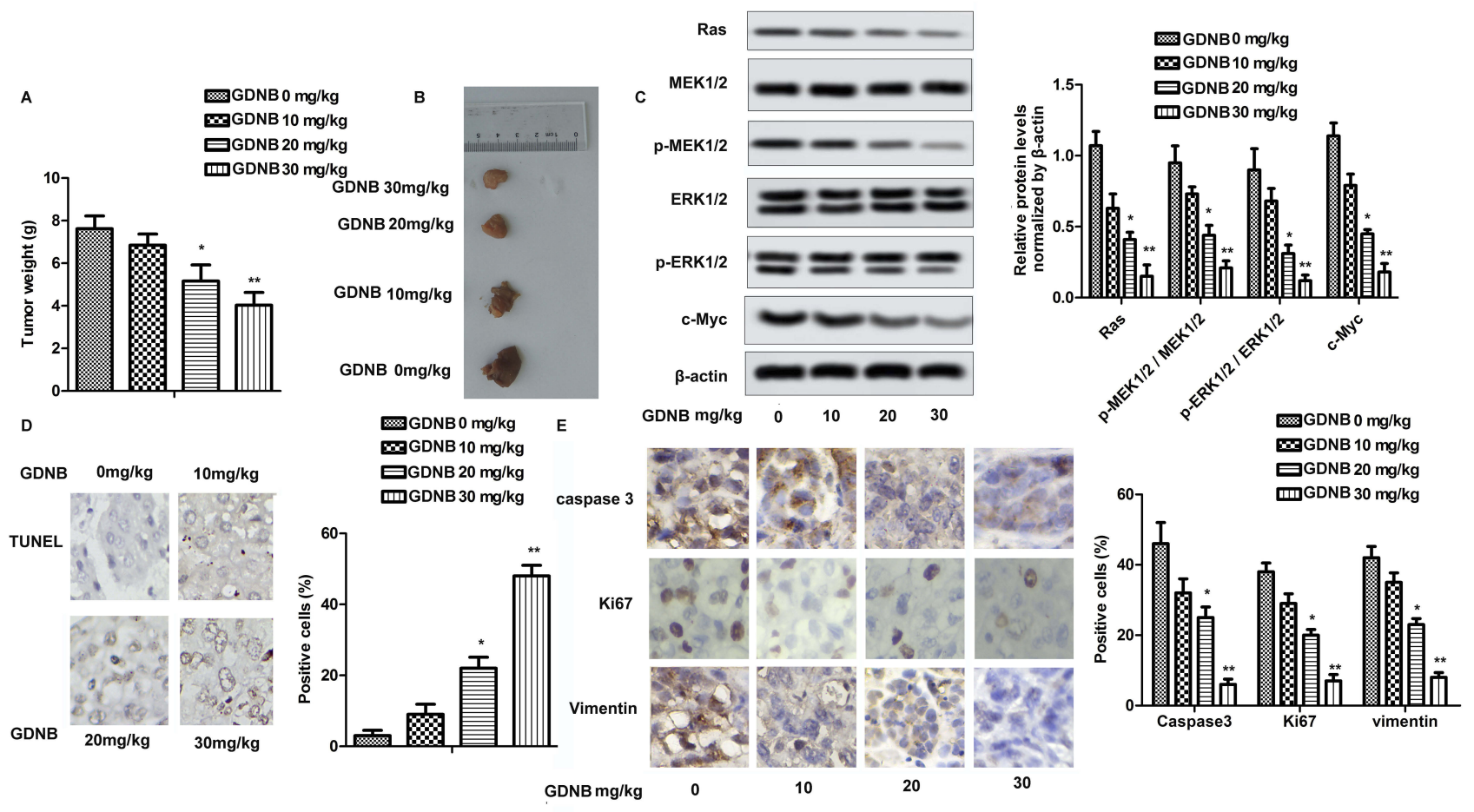

Figure 5 GDNB inhibits tumor formation in vivo through the ERK pathway. Lung tumor-bearing mice were randomly divided into 4 groups (ten in each group): Control group (0.9\% saline) and Administration groups (10, 20, $30 \mathrm{mg} / \mathrm{kg}$ GDNB). (A) Tumor weight. (B) Tumor image. (C) The protein levels of Ras, c-Myc, MEKI/2, P-MEKI/2, ERKI/2 and p-ERKI/2 were measured by Western blotting. (D) The number of apoptotic tumor cells was detected by TUNEL assay. (E) The expression of caspase 3 , ki67 and vimentin in tumor tissues was measured by IHC. $\left({ }^{*} p<0.05, * * p<0.01\right.$ vs control group).

addition of an ERK pathway activator reversed the inhibitory effect of GDNB on the ERK signaling pathway. Furtherly, inactivation of the ERK pathway inhibits proliferation, invasion, migration and EMT of lung cancer cells and induces apoptosis. However, each way was only analyzed the marker proteins by Western blotting. However, this evidence is just one component of numerous orthogonal evidences. Therefore, there is still need other evidence outside of our scope that involves the role of GDNB in non-small cell lung cancer.

In conclusion, this study explored the effects and mechanisms of GDNB on lung cancer formation in vitro and in vivo. Results demonstrate that GDNB significantly inhibits the growth, invasion and migration of lung cancer cells in a dose-dependent manner and prevents EMT processes. Secondly, GDNB can induce apoptosis in lung cancer cells by regulating apoptosis-associated proteins. Mechanism analysis showed that GDNB can inactivate the ERK signal. In short, all data show that GDNB regulates the growth, motility and apoptosis of non-small cell lung cancer cells through ERK signaling pathway.

\section{Disclosure}

The authors report no conflicts of interest in this work.

\section{References}

1. Siegel RL, Miller KD, Jemal A. Cancer statistics, 2017. CA Cancer J Clin. 2017;67(1):7-30. doi:10.3322/caac.21387

2. Ferlay J, Soerjomataram I, Dikshit R, et al. Cancer incidence and mortality worldwide: sources, methods and major patterns in GLOBOCAN 2012. Int $J$ Cancer. 2015;136(5):E359-E386. doi:10. $1002 /$ ijc. 29210

3. Chen W, Zheng R, Baade PD, et al. Cancer statistics in China, 2015. CA Cancer J Clin. 2016;66(2):115-132. doi:10.3322/caac.21338

4. Testa U, Castelli G, Pelosi E. Lung cancers: molecular characterization, clonal heterogeneity and evolution, and cancer stem cells. Cancers. 2018;10(8):E248. doi:10.3390/cancers 10080248

5. Carmichael JA, Wing-San Mak D, O'Brien M. A review of recent advances in the treatment of elderly and poor performance NSCLC. Cancers. 2018;10(7):E236. doi:10.3390/cancers 10070 236

6. Shang J, Xu YD, Zhang YY, Li M. Long noncoding RNA OR3A4 promotes cisplatin resistance of non-small cell lung cancer by upregulating CDK1. Eur Rev Med Pharmacol Sci. 2019;23(10):4220-4225. doi:10.26355/eurrev 20190517926

7. Patel JD, Paz-Ares L, Zinner RG, Barlesi F, Koustenis AG, Obasaju CK. Pemetrexed Continuation Maintenance phase III trials in nonsquamous non-small cell lung cancer: focus on 2-year overall survival and continuum of care. Clin Lung Cancer. 2018;19(6):E823-E830. doi:10.1016/j.cllc.2018.05.013

8. Zhang Y, Jiang Y, Zhang M, Zhang L. Ganoderma sinense polysaccharide: an adjunctive drug used for cancer treatment. Prog Mol Biol Transl Sci. 2019;163:165-177.

9. Zeng P, Chen Y, Zhang L, Xing M. Ganoderma lucidum polysaccharide used for treating physical frailty in China. Prog Mol Biol Transl Sci. 2019;163:179-219. 
10. Zhu J, Xu J, Jiang LL, et al. Improved antitumor activity of cisplatin combined with Ganoderma lucidum polysaccharides in U14 cervical carcinoma-bearing mice. Kaohsiung J Med Sci. 2019;35(4):222-229. doi:10.1002/kjm2.12020

11. Guo J, Yuan C, Huang M, et al. Ganoderma lucidum-derived polysaccharide enhances coix oil-based microemulsion on stability and lung cancer-targeted therapy. Drug Deliv. 2018;25(1):1802-1810. doi:10.1080/10717544.2018.1516006

12. Wu K, Na K, Chen D, Wang Y, Pan H, Wang X. Effects of nonsteroidal anti-inflammatory drug-activated gene-1 on Ganoderma lucidum polysaccharides-induced apoptosis of human prostate cancer PC-3 cells. Int J Oncol. 2018;53(6):2356-2368. doi:10.3892/ ijo.2018.4578

13. Hikino $\mathrm{H}$, Konno $\mathrm{C}$, Mirin Y, Hayashi T. Isolation and hypoglycemic activity of Ganoderans A and B, glycans of Ganoderma lucidum fruit bodies1. Planta Med. 1985;51(04):339-340. doi:10.1055/s-2007-969507

14. Tomoda M, Gonda R, Kasahara Y, Hikino H. Glycan structures of ganoderans $\mathrm{b}$ and $\mathrm{c}$, hypoglycemic glycans of ganoderma lucidum fruit bodies. Phytochemistry. 1986;25(12):2817-2820. doi:10.1016/ S0031-9422(00)83748-6

15. Hikino H, Ishiyama M, Suzuki Y, Konno C. Mechanisms of hypoglycemic activity of ganoderan B: a glycan of Ganoderma lucidum fruit bodies. Planta Med. 1989;55(5):423-428. doi:10.1055/s-2006962057

16. Zhong WD, He HC, Ou RB, et al. Protective effect of ganoderan on renal damage in rats with chronic glomerulonephritis. Clin Invest Med. 2008;31(4):E212-E217. doi:10.25011/cim.v31i4.4782

17. Liu HY, Chen CY, Hung YF, et al. RNase A promotes proliferation of neuronal progenitor cells via an ERK-dependent pathway. Front Mol Neurosci. 2018;11:428. doi:10.3389/fnmol.2018.00428

18. Li J, Guo Y, Duan L, et al. AKR1B10 promotes breast cancer cell migration and invasion via activation of ERK signaling. Oncotarget. 2017;8(20):33694-33703. doi:10.18632/oncotarget.16624

19. Sun Y, Liu WZ, Liu T, Feng X, Yang N, Zhou HF. Signaling pathway of MAPK/ERK in cell proliferation, differentiation, migration, senescence and apoptosis. J Recept Signal Transduct Res. 2015;35(6):600604. doi:10.3109/10799893.2015.1030412

20. Wu D, Li M, Gao Y, et al. Peptide V3 inhibits the growth of human hepatocellular carcinoma by inhibiting the Ras/Raf/MEK/ERK signaling pathway. $J$ Cancer. 2019;10(7):1693-1706. doi:10.7150/ jca. 29211

21. Chen Y, Tang Y, Tang Y, Yang Z, Ding G. Serine protease from nereis virens inhibits H1299 lung cancer cell proliferation via the PI3K/ AKT/mTOR pathway. Mar Drugs. 2019;17(6):E366. doi:10.3390/ md17060366

22. Wei $\mathrm{CH}, \mathrm{Wu} \mathrm{G}$, Cai Q, et al. MicroRNA-330-3p promotes cell invasion and metastasis in non-small cell lung cancer through GRIA3 by activating MAPK/ERK signaling pathway. J Hematol Oncol. 2017;11(1):6. doi:10.1186/s13045-017-0546-4

23. Milovic V, Teller IC, Murphy GM, Caspary WF, Stein J. Deoxycholic acid stimulates migration in colon cancer cells. Eur $J$ Gastroenterol Hepatol. 2001;13(8):945-949. doi:10.1097/00042737-20010800000012

24. Torre LA, Bray F, Siegel RL, Ferlay J, Lortet-Tieulent J, Jemal A. Global cancer statistics, 2012. CA Cancer J Clin. 2015;65(2):87-108. doi: $10.3322 /$ caac. 21262

25. Liu G, Pei F, Yang F, et al. Role of autophagy and apoptosis in nonsmall-cell lung cancer. Int J Mol Sci. 2017;18(2):E367. doi:10.3390/ ijms 18020367
26. Johung KL, Yeh N, Desai NB, et al. Extended survival and prognostic factors for patients with ALK-rearranged non-small-cell lung cancer and brain metastasis. J Clin Oncol. 2016;34(2):123-129. doi:10.1200/JCO.2015.62.0138

27. Zhang S, Pang G, Chen C, et al. Effective cancer immunotherapy by Ganoderma lucidum polysaccharide-gold nanocomposites through dendritic cell activation and memory $\mathrm{T}$ cell response. Carbohydr Polym. 2019;205:192-202. doi:10.1016/j.carbpol.2018.10.028

28. Pan H, Wang Y, Na K, et al. Autophagic flux disruption contributes to Ganoderma lucidum polysaccharide-induced apoptosis in human colorectal cancer cells via MAPK/ERK activation. Cell Death Dis. 2019;10(6):456. doi:10.1038/s41419-019-1653-7

29. Zhang K, Liu Y, Zhao X, et al. Anti-inflammatory properties of GLPss58, a sulfated polysaccharide from Ganoderma lucidum. Int J Biol Macromol. 2018;107(Pt A):486-493. doi:10.1016/j.ijbiomac.2017.09.015

30. Wang J, Cao B, Zhao H, Feng J. Emerging roles of ganoderma lucidum in anti-aging. Aging Dis. 2017;8(6):691-707. doi:10.14336/ AD.2017.0410

31. Zheng J, Yang B, Yu Y, Chen Q, Huang T, Li D. Ganoderma lucidum polysaccharides exert anti-hyperglycemic effect on streptozotocininduced diabetic rats through affecting beta-cells. Comb Chem High Throughput Screen. 2012;15(7):542-550. doi:10.2174/13862071280 1619168

32. Jin H, Jin F, Jin JX, et al. Protective effects of Ganoderma lucidum spore on cadmium hepatotoxicity in mice. Food Chem Toxicol. 2013;52:171-175. doi:10.1016/j.fct.2012.05.040

33. Wang C, Shi S, Chen Q, et al. Antitumor and Immunomodulatory activities of Ganoderma lucidum polysaccharides in glioma-bearing rats. Integr Cancer Ther. 2018;17(3):674-683. doi:10.1177/1534735 418762537

34. Zhao X, Zhou D, Liu Y, et al. Ganoderma lucidum polysaccharide inhibits prostate cancer cell migration via the protein arginine methyltransferase 6 signaling pathway. Mol Med Rep. 2018;17(1):147-157. doi:10.3892/mmr.2017.7904

35. Tao L, Wang S, Zhao Y, et al. Phenolcarboxylic acids from medicinal herbs exert anticancer effects through disruption of COX-2 activity. Phytomedicine. 2014;21(11):1473-1482. doi:10.1016/j.phymed.2014.05. 001

36. Liu QQ, Zhang FF, Wang F, et al. TIPE2 inhibits lung cancer growth attributing to promotion of apoptosis by regulating some apoptotic molecules expression. PLoS One. 2015;10(5):e0126176. doi:10.1371/ journal.pone.0126176

37. Tang F, Tang S, Guo X, Yang C, Jia K. CT45A1 siRNA silencing suppresses the proliferation, metastasis and invasion of lung cancer cells by downregulating the ERK/CREB signaling pathway. Mol Med Rep. 2017;16(5):6708-6714. doi:10.3892/mmr.2017.7466

38. Yue SJ, Zhang PX, Zhu Y, et al. A ferulic acid derivative FXS-3 inhibits proliferation and metastasis of human lung cancer A549 cells via positive JNK signaling pathway and negative ERK/p38, AKT/ mTOR and MEK/ERK signaling pathways. Molecules. 2019;24(11): E2165. doi:10.3390/molecules24112165

39. Chang L, Fang S, Chen Y, et al. Inhibition of FASN suppresses the malignant biological behavior of non-small cell lung cancer cells via deregulating glucose metabolism and AKT/ERK pathway. Lipids Health Dis. 2019;18(1):118. doi:10.1186/s12944-019-1058-8

40. Jiang M, Zhou LY, Xu N, An Q. Hydroxysafflor yellow A inhibited lipopolysaccharide-induced non-small cell lung cancer cell proliferation, migration, and invasion by suppressing the PI3K/AKT/mTOR and ERK/MAPK signaling pathways. Thorac Cancer. 2019;10 (6):1319-1333. doi:10.1111/1759-7714.13019 


\section{Publish your work in this journal}

OncoTargets and Therapy is an international, peer-reviewed, open access journal focusing on the pathological basis of all cancers, potential targets for therapy and treatment protocols employed to improve the management of cancer patients. The journal also focuses on the impact of management programs and new therapeutic agents and protocols on patient perspectives such as quality of life, adherence and satisfaction. The manuscript management system is completely online and includes a very quick and fair peer-review system, which is all easy to use. Visit http://www.dovepress.com testimonials.php to read real quotes from published authors. 